Research Article

\title{
Knowledge Assessment of BSc Nursing 4th Year Students about Breathing Exercises during First Stage of Labour
}

\author{
Sharda Nagvanshi', $\underline{\text { Linson }}^{C^{2}}$ \\ ${ }^{1}$ RKDF College of Nursing, Bhopal, Madhya Pradesh, India. \\ ${ }^{2}$ Department of Nursing, Sarvepalli Radhakrishnan University, Bhopal, Madhya Pradesh, India. \\ DOI: https://doi.org/10.24321/2348.2141.202005
}

\section{I $\quad \mathbf{N} \quad \mathbf{F} \mathbf{O}$}

\section{Corresponding Author:}

Sharda Nagvanshi, RKDF College of Nursing,

Bhopal, Madhya Pradesh, India.

E-mail Id:

shardanagvanshi@gmail.com

Orcid Id:

https://orcid.org/0000-0001-7269-0248

How to cite this article:

Nagvanshi S, Linson CC. Knowledge Assessment of BSc Nursing 4th Year Students about Breathing Exercises during First Stage of Labour. Trends Nurs Adm Edu 2020; 9(2): 17-20.

Date of Submission: 2020-11-28

Date of Acceptance: 2020-12-24

\section{$\begin{array}{llllllll}\mathbf{A} & \mathbf{B} & \mathbf{S} & \mathbf{T} & \mathbf{R} & \mathbf{A} & \mathbf{C} & \mathbf{T}\end{array}$}

Background: For a woman, labour is both the most exciting and the most traumatic experience. Women have varying pain thresholds and deal with pre-labour anxiety in various ways. The aim of this study was to assess the knowledge of BSc Nursing students about breathing exercises that can be done during the first stage of labour.

Methods: An experimental research design with one group pre- and posttest was selected. The sample size was 30 BSc Nursing 4th year students. Demographic data, as well as a self-structured questionnaire was used to assess their level of knowledge regarding breathing exercises.

Result and Conclusion: The post-test knowledge scores o the participants were better than the pre-test knowledge scores. Thus the study clearly shows that there was a significant gain in the knowledge of BSc Nursing students after the interventions on breathing exercise during the first stage of labour.

Keywords: Computer Assisted Instructions, Breathing Exercises, Parturient Mothers in First Stage of Labour, Effect on Labour Outcome

\section{Introduction}

Labour pain is an uncomfortable and distressing experience during the birthing process. It's a very intimate and subjective experience. Many factors influence labour pain, including coping capacity, sensitivity, previous pain experience, birth setting, psychological factors, and so on. The most intense pain a woman will feel in her life is during labour. ${ }^{1}$ A mother's psychological well-being is affected by the severity of her suffering and the length of her labour. It has the potential to lower morale, self-esteem, and anxiety levels. ${ }^{2}$ Lamaze method is a technique of prepared labour and delivery. As it uses the mind (psyche) to prevent labour pain, it is also known as psychoprophylactic method. This method can be used as an alternative to medical intervention during delivery. $^{3}$

\section{Problem Statement}

A study to assess the knowledge of BSc Nursing $4^{\text {th }}$ year students of selected nursing college at Bhopal, (MP) about breathing exercise during first stage of labour

\section{Objectives of the Study}

To assess the knowledge of BSc Nursing $4^{\text {th }}$ year students on breathing exercise during the first stage of labour.

To find out the difference between the pre-test and post-test 
knowledge scores of BSc Nursing students after intervention on breathing exercise during the first stage of labour.

\section{Hypothesis}

$\mathrm{H}$ : There will be a significant difference between pre-test and post-test knowledge scores of the students with the selected nursing intervention.

\section{Research Methodology}

Research Approach: Quantitative approach

Research Design: One Group Pre-test Post-Test Research Design

Setting: Selected Nursing College at Bhopal

Population: BSc Nursing 4th year students

Sampling Technique: Stratified sampling technique

Sample Size: 60

Tools for Data Collection: Self Structured Questionnaire and a PowerPoint presentation on breathing exercises

Duration of Study: 6 weeks

Inclusion Criterion: BSc Nursing students willing to participate in the study

Exclusion Criterion: BSc Nursing students writing supplementary exams

\section{Result}

Frequency and Percentage Distribution of Level of Knowledge of BSc Nursing 4th year Students regarding Breathing Exercises during First Stage of Labour

The data depicts the frequency and percentage distribution of BSc Nursing 4th year students level of awareness about breathing exercise during the first stage of labour. In pre- test, $36.66 \%$ of the BSc Nursing 4th year students had inadequate knowledge regarding the introduction of labour, $60 \%$ had moderate knowledge, and $3.33 \%$ had adequate knowledge. Regarding the breathing exercises technique, $40 \%$ had inadequate knowledge and $60 \%$ had moderate knowledge. Regarding the coping strategy during the first stage of labour, 50\% had inadequate knowledge and 50\% having moderate knowledge. Regarding the advantages of breathing exercises $63.33 \%$ of the students had inadequate knowledge and $36.66 \%$ had moderate knowledge. 53.33\% of the student had inadequate knowledge on partograph, $43.33 \%$ had moderate knowledge and only $3.33 \%$ students had adequate knowledge. $60 \%$ of the participants had inadequate knowledge regarding role of social support in breathing exercise during labour, $33.33 \%$ had moderate knowledge and only $6.66 \%$ had adequate knowledge.

In the post-test, $16.66 \%$ of the BSc Nursing 4 th year students had moderate knowledge regarding the introduction of labour, $60 \%$ and $83.33 \%$ had adequate knowledge. Regarding the breathing exercises technique, $26.66 \%$ had moderate knowledge and $73.33 \%$ had adequate knowledge. Regarding the coping strategy during the first stage of labour $6.66 \%$ had inadequate knowledge, $10 \%$ had moderate knowledge and 83.33\% had adequate knowledge. $3.33 \%$ of the students had inadequate knowledge about the advantages of breathing exercises, $16.66 \%$ had moderate knowledge and $80 \%$ of the students having adequate knowledge. $23.33 \%$ of the students had moderate knowledge on partograph and $76.66 \%$ had adequate knowledge. Regarding the role of social support in breathing exercise during labour $6.66 \%$ had moderate knowledge and $93.33 \%$ of the students had adequate knowledge.

Thus it is evident that the level of knowledge of BSc Nursing students had increased after the nursing intervention was given to them. It concludes that the hypothesis is accepted.

Table I.Frequency and Percentage Distribution of Knowledge of BSc Nursing 4th year Students regarding Breathing Exercises during First Stage of Labour

$(n=60)$

\begin{tabular}{|c|c|c|c|c|c|c|c|c|c|c|c|c|}
\hline \multirow{3}{*}{ Content } & \multicolumn{4}{|c|}{ Inadequate Knowledge } & \multicolumn{4}{|c|}{ Moderate Knowledge } & \multicolumn{4}{|c|}{ Adequate Knowledge } \\
\hline & \multicolumn{2}{|c|}{ Pre-test } & \multicolumn{2}{|c|}{ Post -test } & \multicolumn{2}{|c|}{ Pre- test } & \multicolumn{2}{|c|}{ Post -test } & \multicolumn{2}{|c|}{ Pre -test } & \multicolumn{2}{|c|}{ Post -test } \\
\hline & f & $\%$ & f & $\%$ & f & $\%$ & f & $\%$ & f & $\%$ & f & $\%$ \\
\hline Introduction to labour & 22 & 36.66 & 00 & 00 & 36 & 60 & 10 & 16.66 & 02 & 3.33 & 50 & 83.33 \\
\hline Breathing exercises technique & 24 & 40 & 00 & 00 & 36 & 60 & 16 & 26.66 & 00 & 00 & 44 & 73.33 \\
\hline $\begin{array}{c}\text { Coping strategy during first stage } \\
\text { of labour }\end{array}$ & 30 & 50 & 04 & 6.66 & 30 & 50 & 06 & 10 & 00 & 00 & 50 & 83.33 \\
\hline Advantages of breathing exercises & 38 & 63.33 & 02 & 3.33 & 22 & 36.66 & 10 & 16.66 & 00 & 00 & 48 & 80 \\
\hline Knowledge on partograph & 32 & 53.33 & 00 & 00 & 26 & 43.33 & 14 & 23.33 & 02 & 3.33 & 46 & 76.66 \\
\hline $\begin{array}{c}\text { Role of social support in breathing } \\
\text { exercise during labour }\end{array}$ & 36 & 60 & 00 & 00 & 20 & 33.33 & 04 & 6.66 & 04 & 6.66 & 56 & 93.33 \\
\hline
\end{tabular}




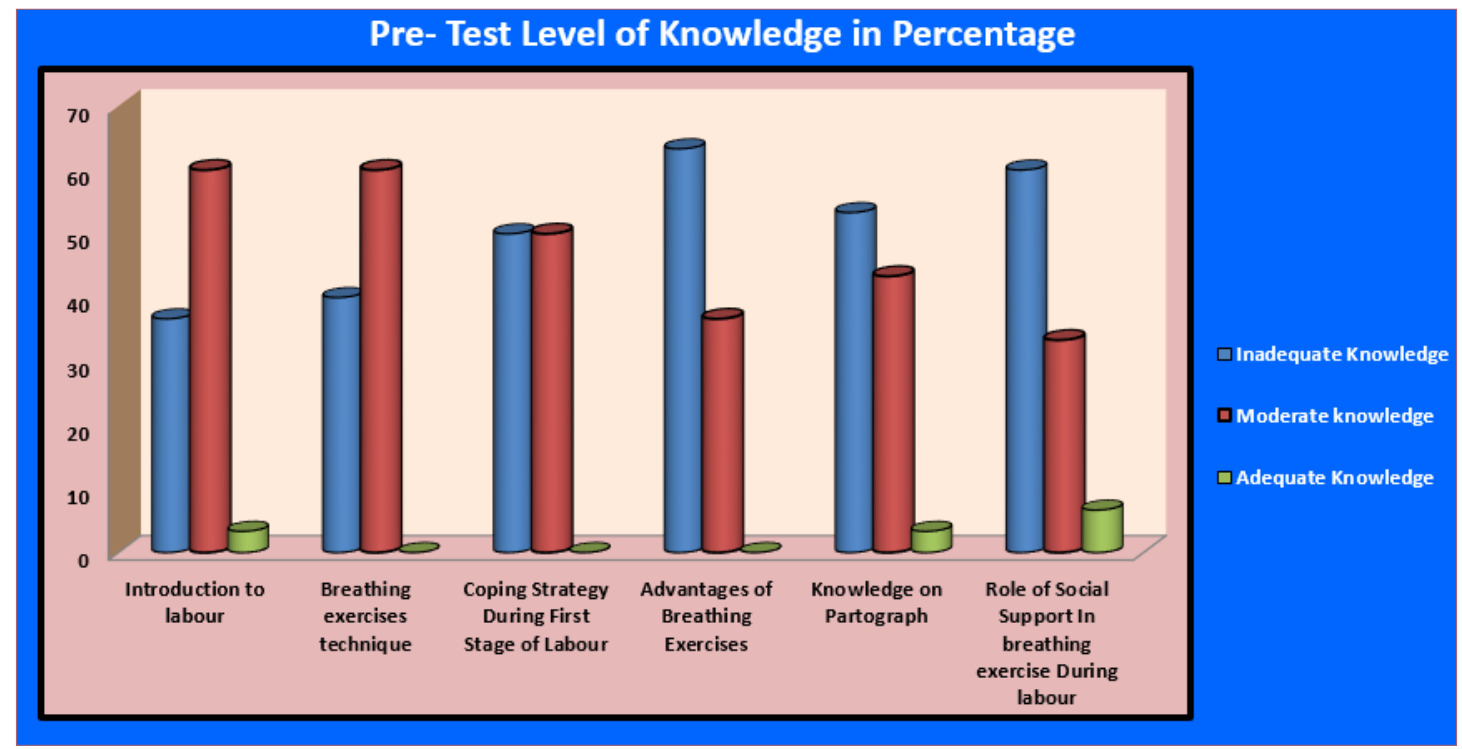

Figure I.Pre-test Level of Knowledge of Subjects regarding Breathing Exercises during First Stage of Labour

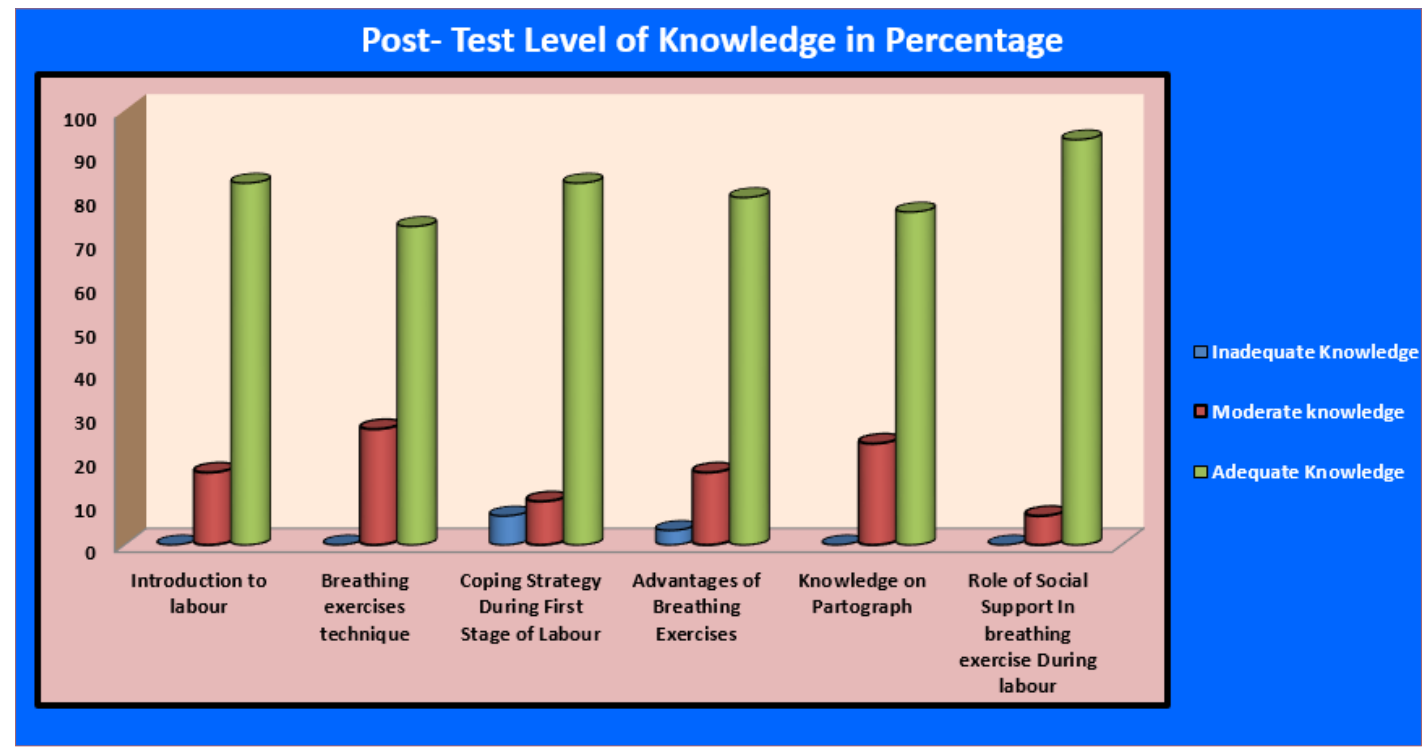

Figure 2.Post-test Level of Knowledge of the Students regarding Breathing Exercises during First Stage of Labour

\section{Discussion}

It's not all about waiting to give birth while you're pregnant. It is often a defining period in a woman's life; it can be a happy and enjoyable experience. For a very few, it may also be a source of pain and suffering. The level of pain that women feel during labour is influenced by a variety of physiological and psychosocial factors. ${ }^{4}$

For several years, complementary and natural therapies have been used to alleviate labour pain. Despite reports that some of these approaches minimise discomfort, improve maternal satisfaction, and improve other obstetrical outcomes, medical literature has given them little attention. Breathing exercises are one of the most common complementary treatments that have been shown to help with labour and delivery. ${ }^{5}$

The analysis is backed up by Dengsangluri Salunkhe JA's research. The research was conducted on 48 participants (24 in the experimental group and 24 in the control group) who were randomly assigned to the groups. During the active phase of labour, the experimental group received breathing exercise during contractions at a rate of three at every 45 minutes intervals, while the control group received routine treatment. Wong Weber's facial pain scale and a behavioural checklist were used to measure pain levels following each contraction. The results revealed a substantial difference between the experimental and control groups' mean pain scores ( $p=0.001$ according to the $t$-test). As a result, at 0.05 
level of significance, the null hypothesis is dismissed. As a result, breathing exercises can help reduce the severity of labour pain during the first stage of labour. Breathing exercises may thus be used in clinical practice to enhance labour and delivery care quality. ${ }^{6}$

\section{Conclusion}

There was a significant increase in the knowledge level of BSc Nursing 4th year students with the selected nursing interventions on breathing exercises. These exercises can be utilised to promote comfort to parturient mothers and minimise the chances for LSCS and instrumental deliveries.

\section{Recommendation}

- On the basis of the study that had been conducted, the following suggestions are given for future studies.

- The study's findings can be repeated on a broad scale to confirm their generalisability.

- The research could take place at various levels of community health.

- An experimental study could be performed to compare the awareness of primigravida women who were subjected to a proposed standardised health education programme on breathing exercises to primigravida women who were not.

- Regular health educational programmes should be conducted by health personnel related to breathing exercises in pregnancy.

\section{Ethical Clearance}

Permission was taken from the concerned authorities and informed consent was obtained from the participants. Confidentiality and privacy of data were maintained.

\section{Source of Funding: Self}

\section{Conflict of Interest: None}

\section{References}

1. Whitburn LY, Jones LE, Davey MA, Small R. The meaning of labour pain: how the social environment and other contextual factors shape women's experiences. BMC Pregnancy Childbirth 2017;17(1):157.

2. Lundgren I, Dahlberg K. Women's experience of pain during childbirth. Midwifery 1998;14(2):105-10.

3. Healthline Parenthood [Internet]. Labor and Delivery: Lamaze Method. Available from: https://www. healthline.com/health/pregnancy/lamaze-methodpain-relief.

4. Cheung W, Ip WY, Chan D. Maternal anxiety and feelings of control during Labour: a study of Chinese first-time pregnant women. Midwifery 2007;23(2):123-30.

5. Reidmann GL. Education for childbirth: Nurse- midwife, female health association. West Suburban Hospital Medical Center, Oak Park, Illinoi. Vol. 2, Chap 18, 2008.
6. Dengsangluri, Salunkhe JA. Effect of breathing exercise in reduction of pain during first stage of labour among primigravidas. Int J Health Sci Res 2015;5(6):390-8. 